\title{
Childhood Ménétriér's disease: A rare cause of exudative enteral protein loss
}

\author{
MARK R OliVER MBBS, CYNTHIA TREVENEN MD, R BRENT SCOTT MDCM
}

\begin{abstract}
MR Oliver, C Trevenen, RB ScotT. Childhood Ménétriér's disease: A rare cause of exudative enteral protein loss. Can J Gastroenterol 1995;9(5): 281-284. A six-year-old boy with Ménétriér's disease, which developed in association with an intercurrent cytomegalovirus (CMV) infection, is presented. This case illustrates the clinical features, natural history and self-limited nature of this rare cause of exudative protein loss in childhood and provides evidence for the association between CMV infection and the pathogenesis of this disorder.
\end{abstract}

Key Words: Cytomegalovirus, Exudative gastropathy, Hypoproteinemia

\section{Maladie de Ménétrier chez l'enfant : Cause rare d'élimination entérique exsudative des protéines}

RÉSUMÉ : Le cas d'un garçonnet de six ans atteint d'une maladie de Ménétrier associée à une infection à cytomégalovirus (CMV) est présenté ici. Ce cas illustre les caractéristiques cliniques, le décours naturel et la résolution spontanée de cette rare cause d'élimination exsudative des protéines chez l'enfant, et décrit les liens que l'on peut établir entre l'infection à CMV et la pathogenèse de la maladie de Ménétrier.

$\mathrm{M}$ ÉNÉTRIÉR'S DISEASE IS A RARE cause of gut-related protein loss in childhood. It was first described by Ménétriér in 1888 (1), and since its initial description there have been only 47 pediatric cases reported (2). The disorder is characterized by an enlargement of gastric rugal folds and characteristic histological changes in full thickness biopsy specimens, and is often associated with hypochlorhydria, hypoproteinemia and edema (2-10). Compared with the adult form of Ménétriér's disease, which follows a chronic pattern often requiring active treatment, the childhood form is usually self-limited. Although the etiology of childhood Ménétriér's disease is unclear, mainly allergic phenomena and infection have been implicated in

Departments of Pathology and Pediatrics, Alberta Children's Hospital and University of

Calgary, Calgary, Alberta

Correspondence and reprints: Dr R Brent Scott, Department of Pediatrics, Health Science

Centre, University of Calgary, 3330 Hospital Drive NW, Calgary, Alberta T2N 4N1

Received for publication July 12, 1994. Accepted January 9, 1995

the pathogenesis. Epidemiological evidence mainly supports cytomegalovirus (CMV), but other microorganisms including Helicobacter pylori and Mycoplasma pneumoniae have been implicated (11-17). This report describes a young child with Ménétriér's disease and provides additional evidence for an association between this disorder and CMV infection in childhood.

\section{CASE PRESENTATION}

A six-year-old Canadian Aboriginal presented to Alberta Children's Hospital following a two-week illness characterized by colicky upper abdominal pain, increasing edema, intermittent nonbilious vomiting and self-limiting nonbloody diarrhea. There were no symptoms to suggest an underlying cardiac, renal, hepatic or lymphatic disorder that might have explained the edema. In addition, there was a negative history for atopy and immunosuppressive disorders. Examination showed him to be a well nourished child with mild pharyngitis and no lymphadenopathy. He had impressive periorbital edema, and pitting edema of his legs up to the knees, small bilateral pleural effusions and abdominal distension with ascites. He also complained of epigastric tenderness on deep palpation. Rectal examination was normal.

Laboratory findings on admission to hospital showed hyponatremia (serum sodium $127 \mathrm{mmol} / \mathrm{L}$ ), hypokalemia (se- 


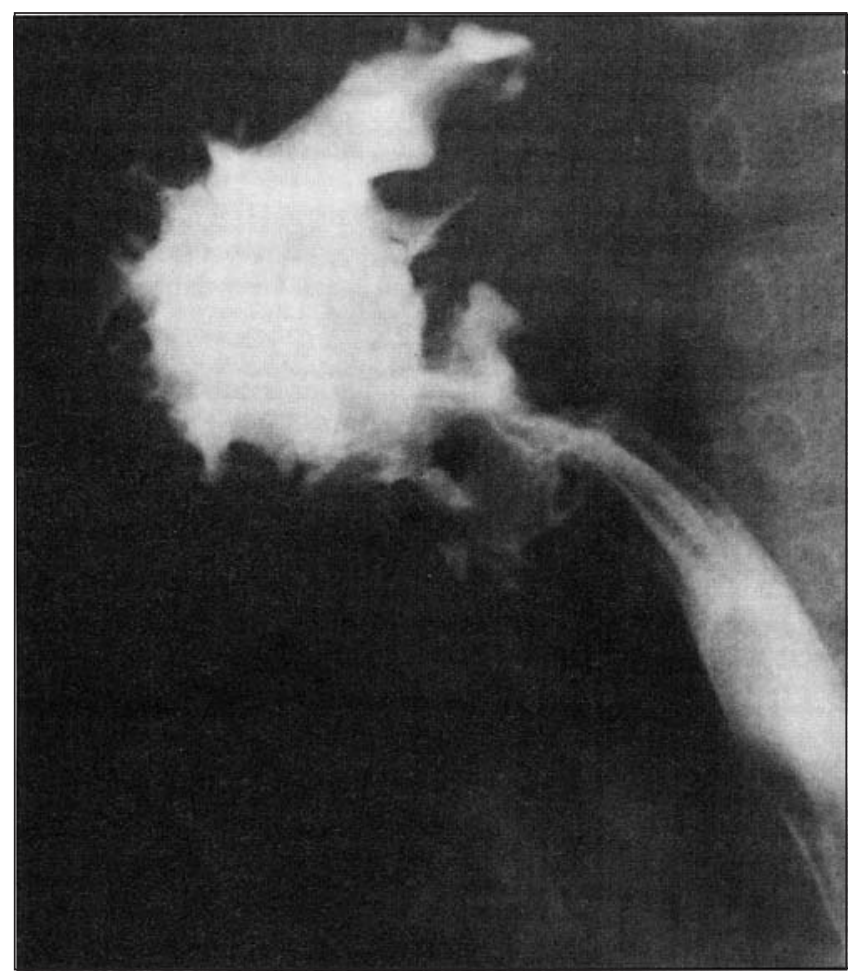

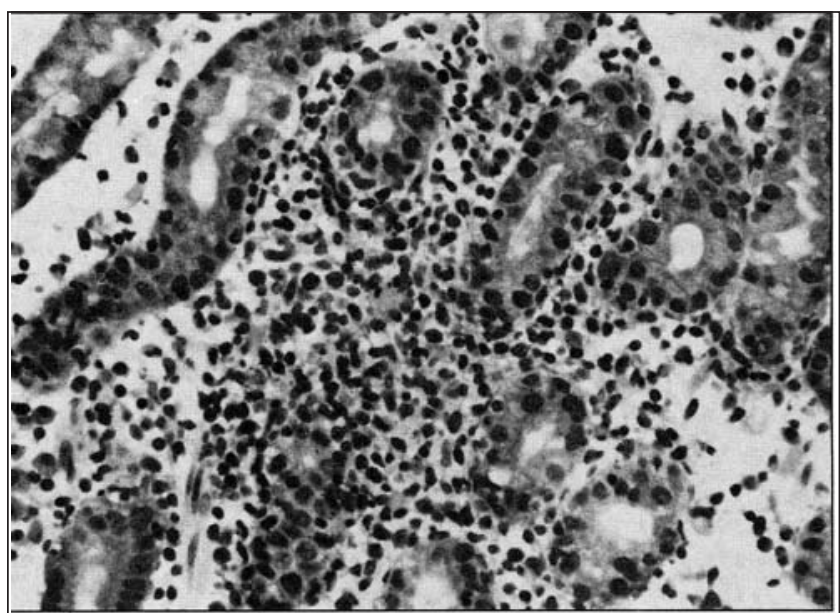

Figure 2) Gastric mucosa focally infiltrated by lymphocytes, plasma cells and eosinophils (original magnification X118)

Figure 1) Left Barium meal demonstrating hypertrophic gastric folds rum potassium $2.8 \mathrm{mmol} / \mathrm{L}$ ) and hypochloremia (serum chloride 94 $\mathrm{mmol} / \mathrm{L})$. Serum albumin was $14 \mathrm{~g} / \mathrm{L}$ (normal range 30 to $50 \mathrm{~g} / \mathrm{L}$ ) and total protein $26 \mathrm{~g} / \mathrm{L}$ (normal range 55 to 75 $\mathrm{g} / \mathrm{L})$ with normal hepatocellular enzymes. Urine analysis was consistently negative for both protein and blood. A complete blood count demonstrated normal hemoglobin, white blood cell and platelet counts. The differential showed no lymphopenia, but peripheral eosinophilia with an absolute count of $1.2 \times 10^{9} / \mathrm{L}$ (normal range 0.1 to $0.7 \times 10^{9}$ ). Immunoglobulin $G$ levels were low at $3.16 \mathrm{~g} / \mathrm{L}$ (normal range 6.33 to $12.8 \mathrm{~g} / \mathrm{L}$ ), but other immunoglobulin levels were normal. Plain $\mathrm{x}$-rays of his abdomen and chest, and an abdominal ultrasound demonstrated bilateral pleural effusions and ascitic fluid without other significant abnormalities.

Stool cultures were positive for the trophozoites of Entamoeba histolytica and Entamoeba nana without any pus or red blood cells. A fluoroscopy guided duodenal aspirate and small bowel biopsy performed using a Carey capsule (Precise Products Corporation, Minnesota) excluded Giardia lamblia enteritis and bacterial overgrowth and demon- strated normal duodenal histology. A $72 \mathrm{~h}$ fecal $\alpha-1$ antitrypsin clearance was increased well above the normal range at $0.278 \mathrm{~g} /$ day (normal less than $0.06 \mathrm{~g} /$ day), suggesting a protein losing enteropathy. A limited colonoscopy showed mild confluent inflammation of the distal colon that was histologically confirmed as mild acute nonspecific colitis. He was treated with metronidazole for seven days and indoquinolol for 21 days.

Despite rapid resolution of the vomiting and diarrhea, the patient remained hypoproteinemic with ongoing epigastric pain. A barium upper gastrointestinal series demonstrated diffuse thickening of the gastric folds with free flow of barium into the structurally normal small intestine (Figure 1). An esophagogastroduodenoscopy confirmed marked thickening of the rugal folds in the body of the stomach with sparing of the antrum. The thickened folds appeared gelatinous and hemorrhagic. The esophagus and duodenum had a normal macroscopic appearance that was confirmed histologically. Biopsies of gastric tissue were sent for culture of $\mathrm{H}$ pylori and for viral isolation. Superficial gastric biopsies from the fundus demonstrated chronic gastritis with conserved foveolar epithelium and nonatrophic glands. The lamina propria was expanded by an inflammatory infiltrate including eosinophils (Figure 2). There was no evidence of $\mathrm{H}$ pylori-like organisms or viral inclusion bodies on light microscopy of gastric fundal or antral biopsies.

Cultures of gastric tissue were negative for $H$ pylori. However, both fundal biopsy specimens and urine were subsequently shown to be positive for CMV by an early antigen method that depends on a fluorescein-labelled monoclonal antibody that is specific for CMV and recognizes the immediate early protein of CMV (18). Serology done at six and 12 weeks was positive for complement fixing CMV antibodies. Immunohistochemical studies conducted on both gastric and rectal tissues were negative. Within two and a half months of the onset of symptoms, and without additional therapy, the patient recovered both clinically and biochemically. A follow-up esophagogastroduodenoscopy performed three months after presentation showed both macroscopic and microscopic resolution of the gastric disease. Repeat evaluation of gastric biopsies 
for CMV by the early antigen method were negative. Similarly, a repeat limited colonoscopy showed macroscopic resolution of distal colonic changes with only mild residual microscopic colitis. Stool cultures were now negative for Entamoeba histolytica. Eighteen months following initial presentation he remains completely well.

\section{DISCUSSION}

The diagnosis of Ménétriér's disease was based on the presence of giant hypertrophy of gastric folds seen both radiologically and at endoscopy, hypoalbuminemia with associated enteral protein loss and a histological gastritis that is often associated with hypochlorhydria. As has been previously reported in children with Ménétriér's disease, this patient's clinical course was self-limited and benign (2-8,1013). Although the microscopic appearance of his fundal biopsy was not classical of this disorder (there was no evidence of foveolar hyperplasia and atrophied glands), there was tissue eosinophilia and edema which is seen histologically in this disease. This variation may have been secondary to either sampling error or the superficial nature of the biopsies $(2,9)$. Or it could be that, as in adults, the clinical features of childhood Ménétriér's disease can be divided into at least two distinct histopathological entities, one representing massive foveolar hyperplasia and the other hypertrophic lymphocytic gastritis (19).

It is interesting to note that our patient also presented with diarrhea and mild colitis, and excreted E histolytica trophozoites in his stools. While it is possible that amoebic colitis may have contributed to the enteric protein loss,

ACKNOWLEDGEMENTS: The authors thank Roberta Funk for typing the manuscript. Mark Oliver is a recipient of an Alberta Children's Hospital Foundation Fellowship.

\section{REFERENCES}

1. Ménétriér P. Des polyadenomes gastriques et de leurs rapport avec le cancer de l'estomac. Arch Physiol Norm Pathol (Paris) 1888;32:236-62.

2. Occena RO, Taylor SF, Robinson CC, Sokol RJ. Association of severe hypoproteinemia is not reported as a presenting factor of this infection $(20,21)$. The marked hypoproteinemia in this patient persisted after the treatment of amoebiasis and after resolution of the diarrhea. In addition, the colitis was macroscopically and histologically mild. It is likely that the massive gut-related protein loss observed in this patient was secondary to Ménétriér's disease, which is associated not only with widening of the gastric mucosal tight junctions $(10,22)$ but also with hypochlorhydria. The latter results in significantly less degradation of $\alpha-1$ antitrypsin activity and hence measurable gastric clearance in this disease.

At least four possible factors can contribute to an increased gastric mucosal mass, in health or in response to disease: intraluminal substances such as nutrients or growth factors from the more proximal gut; trophic factors produced locally or by infectious agents; neural stimulation; and immunological phenomena secondary to an autoimmune process or allergy (9). It is likely that in Ménétriér's disease the irritating agent initiates a significant inflammatory reaction (as shown by the presence of gastritis) which then directly or indirectly causes the observed hypertrophic changes through the action of unidentified mediators. It has recently been shown that transforming growth factor- $\alpha$, an epithelial cell mitogen that inhibits gastric acid secretion and increases mucin production, may be involved in the pathogenesis of this disorder $(23,24)$.

The strongest evidence for an etiological factor in the pediatric population is for CMV infection (2-13), although it is difficult to prove such a causative role because of the ubiquitous

cytomegalovirus with Ménétriér's disease in childhood: report of two new cases with a review of literature.

J Pediatr Gastro Nutr 1993;17:217-24.

3. Stillman AE, Sieber O, Monthei U, Pinnas J. Transient protein losing enteropathy and enlarged gastric rugal in childhood. Am J Dis Child 1981;135:29-33.

4. Baber A, Volgberg F, Sumner T, Moran R. Childhood Ménétriér's disease: four new cases and discussion of the literature. Gastrointest Radiol 1986;11:131-6. nature of this organism. The virus could be directly toxic to the gastric mucosa and allow increased macromolecular uptake that, in turn, initiates an allergic response with the typical peripheral eosinophilia observed in this disease. Infection might also suppress specific regulatory $T$ cell subsets and allow an allergic type of response to be manifested (7), or stimulate a local inflammatory response with the release of mediators, eg, tumour necrosis factor- $\alpha$, that provoke a hypertrophic response lasting only as long as the infection is active (2). Of the 47 pediatric patients previously reported as having Ménétriér's disease, only 27 were investigated for CMV infection (2). Nine of these patients $(33 \%)$ had evidence of gastric CMV infection by characteristic intranuclear inclusions, early antigen and/or positive gastric CMV culture. However, only two previously reported cases had evidence of current CMV infection on the basis of viral culture (urine and gastric tissue) and serology (2). In our case, there is not only supportive evidence of current CMV infection (fundal biopsy and urine positive for CMV early antigen), but also a clinical, endoscopic and histological resolution of Ménétriér's disease that was temporally related to clearance of infection. This suggests that CMV had a role in the pathogenesis of the disorder in our patient. A direct causal relationship between gastric CMV infection and Ménétriér's disease in childhood will require a thorough examination for CMV in subsequent patients with this disorder, and further study of both host defence mechanisms and the manner in which they can be altered in CMV infection.

5. Kraut J, Powell R, Hruby M, Lloyd-Still J. Ménétriér's disease in childhood; report of two cases and a review of the literature. J Pediatr Surg 1981;16:707-11.

6. Chouraqui JP, Roy CC, Brochu P, Gregoire H, Morin CL, Weber AM. Ménétriér's diseases in children: Report of a patient and review of sixteen other cases. Gastroenterology 1981;80:1042-7.

7. Coad NA, Shah KJ. Ménétriér's disease in childhood associated with cytomegalovirus infection: a case report 
and review of the literature. Br J Radiol 1986;59:615-20.

8. Bar-Ziv Barki Y, Weizman Z, Urkir J. Transient protein-losing gastropathy (Ménétriér's disease) in childhood. Pediatr Radiol 1988;18:82-4.

9. Sundt TM, Compton CC, Malt RA. Ménétriér's disease. A trivalent gastropathy. Ann Surg 1988;208:694-701.

10. Odera G, Cinti S, Cangiotti A, Forni $\mathrm{M}$, Ansaldi N. Increased tight junction width in two children with Ménétriér's disease. J Pediatr Gastroenterol Nutr 1990;11:123-7.

11. Kovacs AA, Churchill MA, Wood D, Mascola L, Zaia JA. Molecular and epidemiologic evaluations of a cluster of cases of Ménétriér's disease associated with cytomegalovirus. Pediatr Infect Dis J 1993;12:1011-4.

12. Qualman SJ, Hamoudi AB. Pediatric hypertrophic gastropathy (Ménétriér's disease). Pediatr Pathol 1992;12:263-7.

13. Khoshoo V, Alonzo E, Correa H, Levine S, Udall JN Jr. Pathological case of the month. Ménétriér's disease with cytomegalovirus gastritis. Arch Pediatr Adol Med 1994;148:611-2.

14. Morrison S, Dahms BB, Hoffenberg E, Czinn SJ. Enlarged gastric folds in association with Campylobacter pylori gastritis. Radiology 1989;171:819-21.

15. Bayerdorffer E, Ritter MM, Hatz R, Brooks W, Ruckdeschel G. Healing of protein losing hypertrophic gastropathy by eradication of Helicobacter pylori - is Helicobacter pylori a pathogenic factor in Ménétriér's disease? Gut 1994;35:701-4.

16. Bayerdorffer E, Ritter MM, Hatz R, Brooks W, Stolte M. Ménétriér's disease and Helicobacter pylori. N Engl J Med 1993;329:60. (Lett)

17. Lepore MJ, Smith FB, Bonanno CA. Campylobacter-like organisms in patient with Ménétriér's disease. Lancet 1988;1:466.

18. Gleaves CA, Lee CF, Kirsch L, Meyers JD. Evaluation of a direct fluoresceinconjugated monoclonal antibody for detection of cytomegalovirus in centrifugation culture. J Clin Microbiol 1987;25:1548-50.

19. Wolfsen HC, Carpenter HA, Talley
NJ. Ménétriér's disease: A form of hypertrophic gastropathy or gastritis. Gastroenterology 1993;104:1310-9.

20. Reed SL. Amebiasis: an update. Clin Infect Dis 1992;14:385-93.

21. Patterson M, Schoppe L. The presentation of amoebiasis. Med Clin North Am 1982;66:689-704.

22. Kelly D, Miller L, Malagelada K, Huizenga K, Markowitz H. Giant hypertrophic gastropathy (Ménétriér's disease): pharmacological effect on protein leakage and mucosal ultrastructure. Gastroenterology 1982;83:581-9.

23. Dempsey PJ, Goldering JR, Soroka CJ, et al. Possible role of transforming growth factor $\alpha$ in the pathogenesis of Ménétrier's disease: supportive evidence from humans and transgenic mice. Gastroenterology 1992;103:1950-63.

24. Van den Berg M, Stokkers P, Ring E, Buller H. Transforming growth factor $\alpha$ in Ménétrier's disease. J Pediatr Gastroenterol Nutr 1993;17:230-2. 


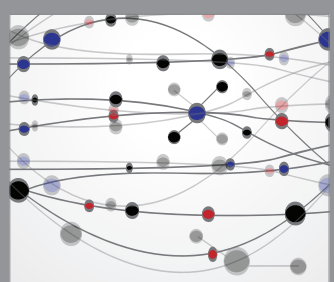

The Scientific World Journal
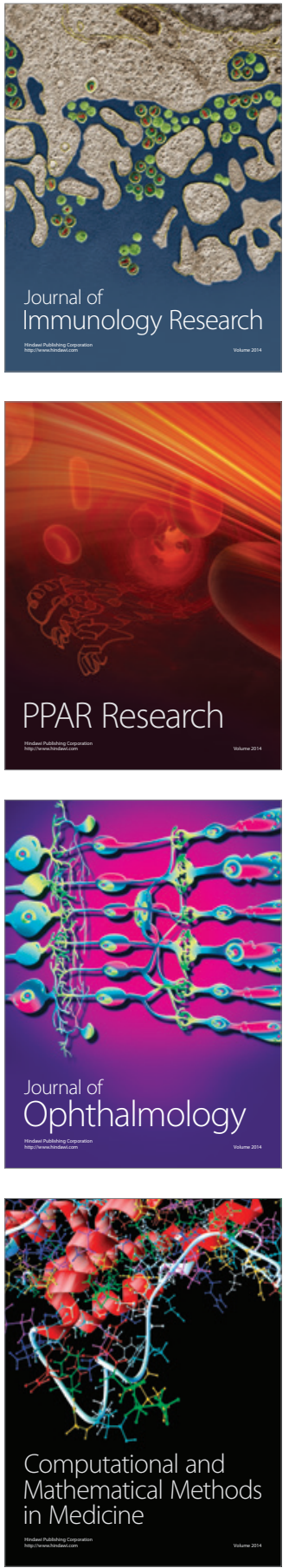

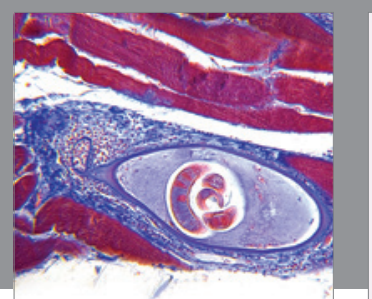

Gastroenterology Research and Practice

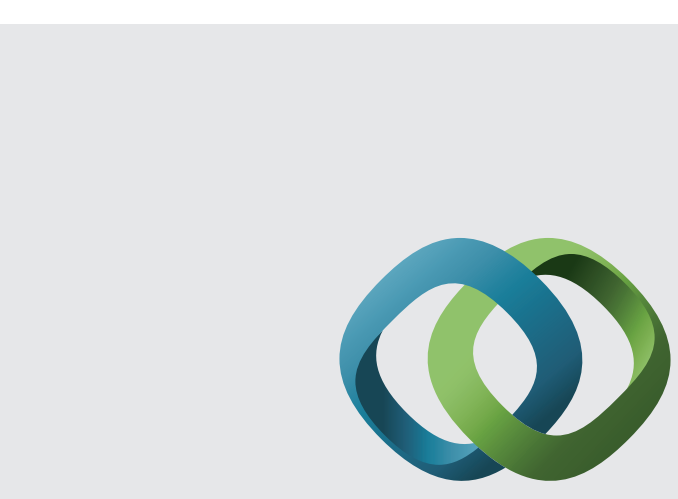

\section{Hindawi}

Submit your manuscripts at

http://www.hindawi.com
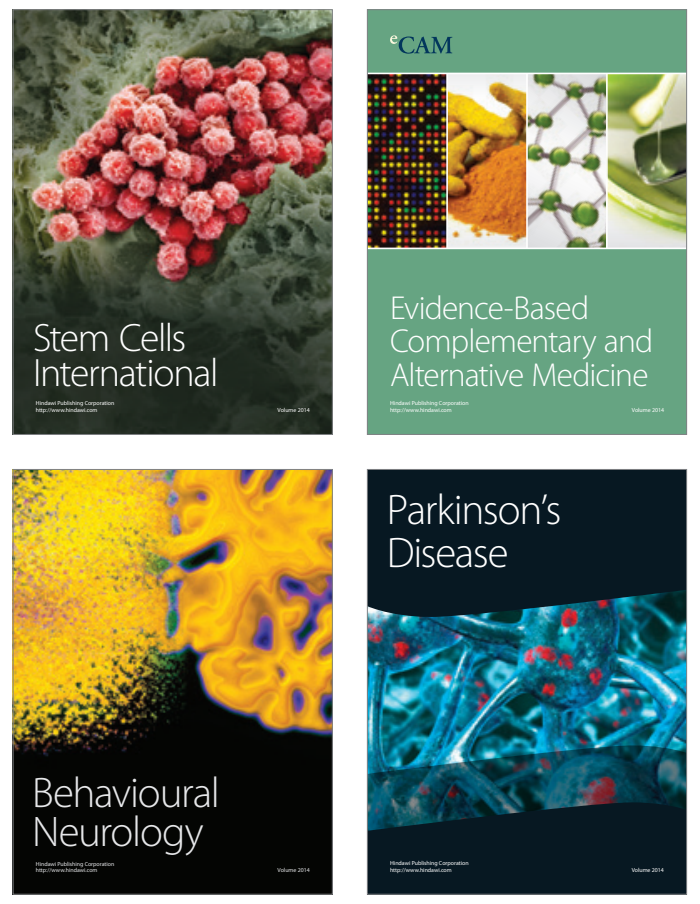
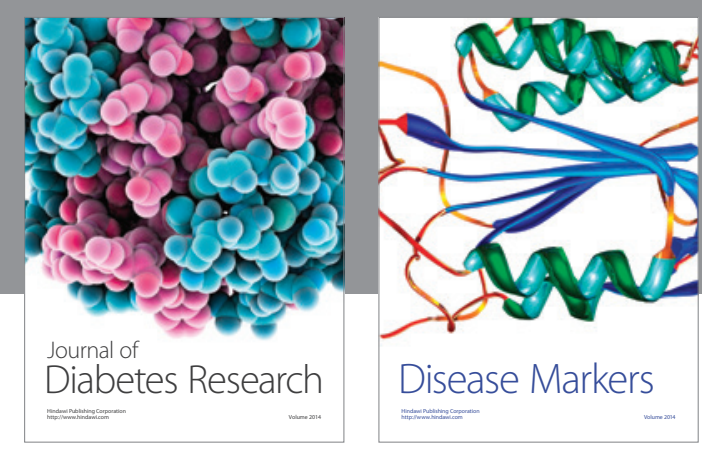

Disease Markers
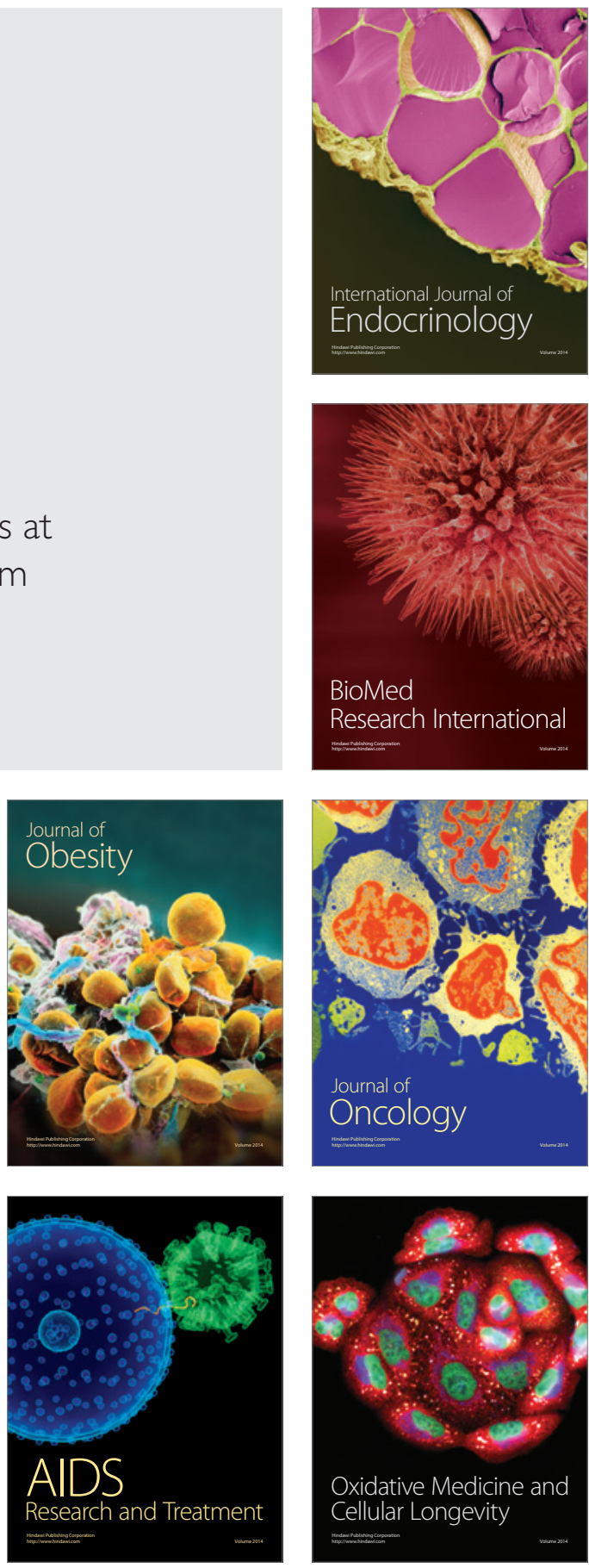